\title{
Condutividade elétrica como indicador do café despolpado durante a desgomagem
}

\author{
Electric conductivity as indicator of coffee depulped during degumming
}

\author{
Matheus Vicente Lima ${ }^{I}$ Henrique Duarte Vieira ${ }^{I^{*}}$ Meire Lélis Leal Martins $^{\mathrm{I}}$
} \begin{abstract}
avaliar a utilização da variável condutividade elétrica do meio desgomante como um indicador dos procedimentos de manejo do café despolpado durante a desgomagem do grão. Os experimentos foram conduzidos em três propriedades cafeeiras da região sudoeste da Bahia, utilizando Coffea arabica L., variedade Catuai Amarelo, para estudar o efeito de dois manejos de água do meio desgomante, dois manejos de revolvimento da solução desgomante e seis períodos de tempo em esquema fatorial. Um aumento da condutividade elétrica foi observado durante a desgomagem do grão, principalmente, no tratamento com revolvimento do meio. A troca de água do meio desgomante mostrou ser necessária, pois, ao longo da desgomagem, ocorreu um equilíbrio eletroquímico no meio, impedindo que a mucilagem continuasse a ser liberada do grão para o meio. Portanto, por meio da condutividade elétrica do meio, é possível indicar o momento em que se deve realizar a troca de água do tanque de desgomagem.
\end{abstract}

Palavras-chave: Coffea arabica L., mucilagem, fermentação.

\section{ABSTRACT}

This research was carried out with the aim to evaluate the use of electric conductivity of the degumming medium as an indicator for management procedures of depulped coffee during degummming of the grain. The experiment was performed in three coffee properties in the Southwest region of Bahia, Brazil, using Coffea arabica L., Yellow Catuai variety. It was studied the effect of two water management of the degumming medium, two management of rummaging of the degumming solution, six time periods in factorial design. An increase on the electrical conductivity values was observed during degumming of coffee grain. Mainly in the treatment where the medium was rummaged. The water

\begin{abstract}
change of the degumming medium showed to be necessary since along the degumming process an electro-chemical equilibrium of the medium was achieved, avoiding that the mucilage was liberated from the grain to the medium. Therefore, the electrical conductivity was possible to indicate when the water change from the degumming tank must be done.
\end{abstract}

Key words: Coffea arabica L., mucilage, fermentation.

Um dos fatores limitantes para a venda do café brasileiro no mercado internacional é a deficiência de um padrão de qualidade do produto nacional (SOUZA, 1996; SIQUEIRA, 2003). O valor do café aumenta, significativamente, com a melhoria da qualidade. Sendo assim, o amplo conhecimento das técnicas de produção de um café de alta qualidade é indispensável para uma cafeicultura moderna. A qualidade do café depende da interação entre fatores da fase de pré e pós-colheita, que garantem ao grão as características de sabor e aroma desejados (CARVALHO et al., 1997; VILLELA, 2002).

No café preparado por via seca, o fruto é seco na sua forma integral, dando origem aos cafés em coco, de terreiro ou natural. Na forma de preparo por via úmida, originam-se os cafés despolpados, desmucilados e cereja descascados (SILVA, 1999). O preparo do café despolpado e desmucilado consiste na retirada da casca e da mucilagem do fruto maduro (PEREIRA et al., 2002). No café cereja descascado (CD), retira-se apenas a casca do fruto e este é levado para

\footnotetext{
'Universidade Estadual do Norte Fluminense Darcy Ribeiro (UENF). Av. Alberto Lamego, $\mathrm{n}^{\circ}$ 2000, Bairro Parque Califórnia,
} 28013-602, Campos de Goytacazes, RJ, Brasil. E-mail: henrique@uenf.br. *Autor para correspondência. 
secagem com a mucilagem aderida ao pergaminho. Durante o preparo do café despolpado, o grão passa por um período de imersão em água para que a mucilagem ainda aderida ao pergaminho seja totalmente liberada. Tal processo é denominado de desgomagem.

Atualmente não existe uma metodologia científica para garantir a obtenção de um café desgomado de ótima qualidade. Assim, este trabalho teve como objetivo avaliar procedimentos de manejo, como o revolvimento e troca de água do meio, durante a desgomagem do café por fermentação natural, utilizando como indicador a condutividade elétrica da solução desgomante.

O trabalho foi realizado em três propriedades cafeeiras da região sudoeste da Bahia: 1) Fazenda Diamante (Ribeirão do Largo-BA), 2) Fazenda Santa Fé (Planalto-BA), 3) Fazenda Ouro Verde (Vitória da Conquista-BA). Essas propriedades estão localizadas a $850 \mathrm{~m}$ de altitude, com precipitações médias de $1.200 \mathrm{~mm}$, concentradas na primavera-verão. As lavouras são irrigadas e recebem todos os tratos culturais necessários à produção de café de boa qualidade.

O experimento foi realizado durante os meses de julho e agosto de 2005, em lavouras de café com 15 anos de idade e 3.000 plantas ha ${ }^{-1}$, da variedade Catuaí Amarelo. O café foi colhido a dedo, sobre pano e levado para processamento no mesmo dia. O café colhido foi lavado, descascado e encaminhado aos taques de desgomagem onde foram realizados os tratamentos.

A desgomagem ocorreu por fermentação natural em água, em tambores plásticos com capacidade para 120 litros. Os tambores foram posicionados ao lado dos tanques de desgomagem das propriedades em local descoberto. Os tambores continham 80 litros de café descascados e 38 litros de água, suficiente para submersão dos grãos a $3 \mathrm{~cm}$ da superfície da massa.

O delineamento experimental adotado foi o inteiramente casualizado, com três repetições, em esquema fatorial 2x2x6 (dois manejos de troca de água do tanque, dois manejos de revolvimento da solução desgomante em seis períodos de tempo).

O revolvimento da solução ocorreu de quatro em quatro horas, por meio do revolvimento da massa desgomante, em movimentos circulares e verticais nos tambores, durante um minuto, utilizando uma régua de madeira de $1,5 \mathrm{~m}$. A troca de água ocorreu de 12 em 12 horas, sendo colocada uma nova água, com o mesmo volume anterior.

Durante a desgomagem, amostras de dois litros da solução café mais a água do meio desgomante foram retiradas utilizando um cano de pvc de duas polegadas, a fim de retirar uma amostra representativa de todo o perfil do tanque. As amostras foram retiradas nos períodos de zero, 6,12 ,
18, 24 e 30h após o início da desgomagem e então foi realizada a leitura da condutividade elétrica, por meio de um condutivímetro portátil, Conductivity Meter CD-4303.

O início da desgomagem foi considerado o ponto em que a água foi adicionada aos tanques contendo o café. No momento em que coincidia a leitura da variável com o revolvimento da solução, a leitura ocorria antes do revolvimento. No momento da troca de água foram realizadas leituras antes e após a troca.

Os valores das leituras posteriores à troca de água não foram inseridos na análise estatística, sendo considerados apenas como indicadores do que ocorria com o meio desgomante no momento da troca.

Os dados foram submetidos à análise de variância com aplicação do Teste $\mathrm{F}$ a $5 \%$ de probabilidade. Os graus de liberdade dos tratamentos foram desdobrados via teste de comparação de médias, utilizando-se o Teste de Tukey a 5\% de probabilidade. Procedeu-se a análise estatística individual dos resultados obtidos nas três propriedades, considerando-se em todos os casos os fatores em estudo e sua interação com o ambiente.

Houve diferença significativa para a variável condutividade elétrica do meio desgomante, para os fatores isoladamente e para a interação entre eles. Nas propriedades 2 e 3 foi observado interação tripla entre os fatores, enquanto que na propriedade 1 ocorreu interação com revolvimento do meio em função do tempo de desgomagem e troca de água do meio em função do tempo de desgomagem.

Em todas as propriedades foi observado um aumento significativo da condutividade elétrica do meio desgomante em função do tempo de desgomagem do grão de café (Figura 1). Este aumento na condutividade elétrica foi associado à liberação de mucilagem do grão. Comparando os tratamentos com revolvimento e sem revolvimento, em um mesmo intervalo de tempo, observou-se que nos tratamentos em que ocorreu revolvimento houve um aumento significativo da condutividade elétrica em relação ao que não sofreu revolvimento (Tabela 1 ).

O revolvimento do meio desgomante estimula o crescimento de microrganismos aeróbicos, que ao atuar sobre as substâncias pécticas presentes na lamela média e membrana celular, promovem uma desintegração das mesmas, ocorrendo a lixiviação de sais citoplasmáticos para o meio desgomante (AVALLONE et al., 2001). Neste trabalho foi observado que o revolvimento da solução acelerou o processo de desgomagem. Os grãos dos tratamentos com revolvimento apresentavam-se despolpados mais rapidamente.

O revolvimento da solução proporcionou um aumento de $654 \%$ no valor da condutividade elétrica 


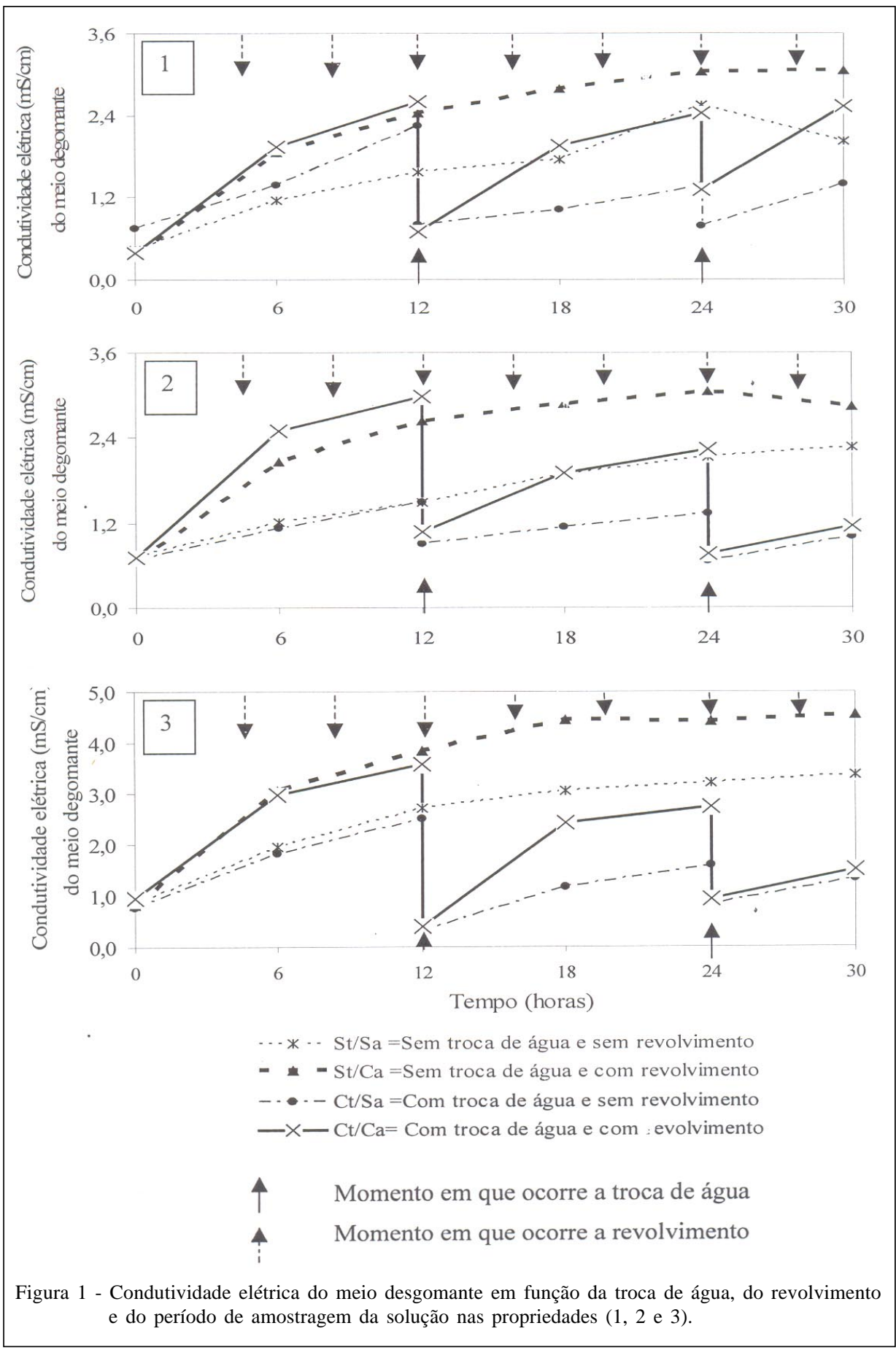

do meio, enquanto que o tratamento não-revolvido proporcionou um aumento de apenas $183 \%$ no valor da condutividade elétrica comparando o período inicial e o final (30 horas de desgomagem), na propriedade 1 (Tabela 1). Na propriedade 2, os percentuais de aumento dos valores dos tratamentos com e sem revolvimento foram de $430 \%$ e $315 \%$, respectivamente, no mesmo período. Na propriedade 3 , os percentuais de aumento dos valores dos tratamentos com e sem revolvimento foram, respectivamente, 549\% e 407\%.

Em relação ao tratamento sem troca de água do meio e com revolvimento do meio desgomante, foi observado que após 18 horas de desgomagem dos grãos ocorreu uma estabilização da condutividade elétrica do meio principalmente nas propriedades 2 e 3 (Tabela 1). Isso, provavelmente, foi ocasionado pela 
Tabela 1 - Valores médios da condutividade elétrica do meio desgomante $\left(\mathrm{mS} \mathrm{cm}^{-1}\right)$ em função do seu revolvimento e do tempo de desgomagem, nas Propriedades (1, 2 e 3).

\begin{tabular}{|c|c|c|c|c|c|c|}
\hline \multicolumn{7}{|l|}{ Propriedade 1} \\
\hline Trat/tempo & Oh & $6 \mathrm{~h}$ & $12 \mathrm{~h}$ & $18 \mathrm{~h}$ & $24 \mathrm{~h}$ & $30 \mathrm{~h}$ \\
\hline Sem revolvimento & $0,60 \mathrm{dA}$ & $1,26 \mathrm{cB}$ & $1,90 \mathrm{aB}$ & $1,38 \mathrm{bcB}$ & $1,95 \mathrm{aB}$ & 1,70abB \\
\hline Com revolvimento & $0,37 \mathrm{dA}$ & $1,90 \mathrm{cA}$ & 2,51abA & $2,37 \mathrm{bA}$ & 2,74abA & $2,79 \mathrm{aA}$ \\
\hline $\mathrm{CV}$ & $13,46 \%$ & & & & & \\
\hline \multicolumn{7}{|l|}{ Propriedade 2} \\
\hline Trat/tempo & $0 \mathrm{~h}$ & $6 \mathrm{~h}$ & $12 \mathrm{~h}$ & $18 \mathrm{~h}$ & $24 \mathrm{~h}$ & $30 \mathrm{~h}$ \\
\hline Sem revolvimento & $0,72 \mathrm{dA}$ & $1,21 \mathrm{cB}$ & $1,49 \mathrm{cB}$ & $1,89 \mathrm{bB}$ & 2,12abB & $2,27 \mathrm{aB}$ \\
\hline Com revolvimento & $0,66 \mathrm{dA}$ & $2,06 \mathrm{cA}$ & $2,62 \mathrm{bA}$ & 2,87abA & $3,04 \mathrm{aA}$ & $2,84 \mathrm{abA}$ \\
\hline $\mathrm{CV}$ & 8,27 & & & & & 0 \\
\hline \multicolumn{7}{|l|}{ Propriedade 3} \\
\hline Trat/tempo & $0 \mathrm{~h}$ & $6 \mathrm{~h}$ & $12 \mathrm{~h}$ & $18 \mathrm{~h}$ & $24 \mathrm{~h}$ & $30 \mathrm{~h}$ \\
\hline Sem revolvimento & $0,83 \mathrm{dA}$ & $1,96 \mathrm{cB}$ & $2,72 \mathrm{bB}$ & 3,05abB & $3,21 \mathrm{aB}$ & $3,38 \mathrm{aB}$ \\
\hline Com revolvimento & $0,83 \mathrm{dA}$ & $3,05 \mathrm{cA}$ & $3,84 \mathrm{bA}$ & $4,44 \mathrm{aA}$ & 4,43aA & $4,56 \mathrm{aA}$ \\
\hline $\mathrm{CV}$ & 6,84 & & & & & \\
\hline
\end{tabular}

Médias seguidas pelas mesmas letras, minúsculas nas linhas e maiúsculas nas colunas, não diferem entre si pelo teste de Tukey a 5\% de probabilidade.

saturação do meio desgomante, formando uma barreira eletroquímica capaz de impedir que o processo de desmucilagem do grão continuasse. Portanto, a estabilidade da condutividade elétrica do meio pode ser um bom indicativo do momento ideal para a troca de água do tanque, porém, deve ser avaliada a necessidade da segunda troca de água, após 24 horas de desgomagem, já que o meio ainda era capaz de receber solutos (Figura 1).

A condutividade elétrica pode ser utilizada como um indicador do momento em que deve ser realizada a troca de água do meio desgomante.

O revolvimento da solução acelera o processo de desgomagem do grão de café e a troca de água do tanque possibilita a solução desgomante receber mais solutos, o que evita que o grão de café permaneça em uma solução ácida, altamente concentrada, minimizando a possibilidade de ocorrência de fermentações indesejáveis.

\section{REFERÊNCIAS}

AVALLONE, S. et al. Microbiological and biochemical study of coffee fermentation. Current Microbiology, v.42, p.252256, 2001.
CARVALHO, V.D. et al. Fatores que afetam a qualidade do café. Informe Agropecuário, v.18, n.187, p.5-20, 1997.

PEREIRA, R.G.F.A. et al. Composição química de grãos de café (Coffea arabica L.) submetidos a diferentes tipos de préprocessamento. In: SIMPÓSIO DE PESQUISA DOS CAFÉS DO BRASIL, 2., (2002), Vitória-ES. Resumos... Vitória: FUNCAFÉ, 2002. p.826-831.

SILVA, J.S. Colheita, secagem e armazenagem do café. In: ZAMBOLIM, L. (Ed.). I Encontro sobre produção de café com qualidade. Viçosa: UFV, 1999. p.39-80.

SIQUEIRA, H.H. Análises físico-químicas, químicas e sensoriais de diferentes tipos de processamento durante a torração. 2003. 57f. Dissertação (Mestrado em Ciência dos Alimentos) - UFLA, Lavras, MG.

SOUZA, S.C.M. O café (Coffea arabica L.) na região Sul de Minas Gerais: relação da qualidade com fatores ambientais, estruturais e tecnológicos. 1996. 171f. Tese (Doutorado em Fitotecnia) - UFLA, Lavras, MG.

VILLELA, T.C. Qualidade do café despolpado, desmucilado, descascado e natural, durante o processo de secagem. 2002. 69f. Dissertação (Mestrado em Ciência dos Alimentos) - UFLA, Lavras, MG. 